\title{
Evaluasi Kebijakan Pemerintah Pasca Bencana (Studi Kasus Bencana di Sulawesi Tengah)
}

\author{
${ }^{1}$ Muhammad Ahsan Samad, ${ }^{2}$ Erdiyansyah, ${ }^{3}$ Rina Wulandari \\ ${ }^{123}$ Program Studi Administrasi Publik, Universitas Tadulako \\ Palu, Indonesia, 94119
}

E-mail: ahsansamad@untad.ac.id ; erdiyansyah@untad.ac.id ; rinawulandariofficial@gmail.com

Received: 29 Februari 2020; Revised: 17 Maret 2020; Accepted: 02 Mei 2020

\begin{abstract}
The purpose of this study is to identify and describe the impact and behavior of the community on post-disaster economic conditions in the city of Palu and to know the local government's public policies in handling these cases. Using qualitative methods with a case study approach, literature study, and secondary data processing from various social elements. In addition, data collection was carried out by interviewing informants who felt the direct impact of the earthquake, tsunami and liquefaction in Palu, Sigi and Donggala. The results showed that the post-disaster impact felt by the people of Palu City was generally in the "severe" classification. The socio-economic conditions of the people of Palu include several aspects, ranging from the geographical conditions that are in disasterprone zones, to the extremely poor health conditions after the disaster. The conclusion of this research shows that the escalation of natural disasters in the city of Palu is considered quite large because it consists of three types of disasters, namely the Earthquake, Tsunami and Liquifation in the same time period. Palu City is the capital of the Province as well as the economic and administrative center of Central Sulawesi Province. Damage to warehousing infrastructure coupled with massive looting from unscrupulous people in logistics supply warehouses resulted in goods that were supposed to be distributed both to the city and the district finally unable to be implemented.
\end{abstract}

Keywords: Policy; Disaster; Economic; Social

\begin{abstract}
Abstrak
Tujuan penelitian ini yaitu mengidentifikasi dan mendeskripsikan evaluasi dampak dan perilaku masyarakat terhadap kondisi perekonomian pasca bencana di kota Palu dan mengetahui kebijakan publik pemerintah setempat dalam menangani kasus tersebut. Menggunakan metode kualitatif dengan pendekatan studi kasus, studi literature, dan pengolahan data sekunder dari berbagai elemen sosial. Selain itu pengambilan data dilakukan dengan cara wawacara kepada narasumber yang merasakan dampak langsung dari bencana gempa,tsunami dan likuifaksi di Palu,Sigi dan Donggala. Hasil penelitian memperlihatkan bahwa dampak pasca bencana yang dirasakan oleh masyarakat Kota Palu secara umum berada pada klasifikasi "berat". Kondisi sosial ekonomi masyarakat kota Palu meliputi beberapa aspek, mulai dari kondisi geografis yang berada pada zona rawan bencana, kondisi kesehatan sangat memprihatinkan pasca bencana. Kesimpulan penelitain ini menujukkan bahwa eskalasi bencana alam kota Palu dinilai cukup besar karena terdiri dari tiga macam bencana yaitu Gempa Bumi, Tsunami dan Liquifasi dalam kurun waktu sama. Kota Palu merupakan ibukota Provinsi sekaligus sebagai pusat ekonomi dan pemerintahan Provinsi Sulawesi Tengah. Rusaknya infrakstruktur pergudangan ditambah dengan adanya penjarahan yang massiv dari oknum masyarakat pada gudanggudang suplai logistik mengakibatkan barang yang semestinya didistribusikan baik ke kota ataupun ke kabupaten akhirnya tidak dapat dilaksanakan.
\end{abstract}

Kata Kunci: Kebijakan; Bencana; Ekonomi; Sosial

Link DOI : http://dx.doi.org/10.31314/pjia.9.1.15-24.2020 


\section{PENDAHULUAN}

Kerusakan yang disebabkan oleh gempa bumi meningkat seiring dengan pertumbuhan populasi yang cepat dan peningkatan permukiman di daerah-daerah rawan gempa bumi (Rusydi, Effendi, \& Rahmawati, 2017).Bencana alam seperti gempa yang terjadi di Donggala,Palu dan sekitarnya bukan hanya mengakibatkan korban jiwa, tetapi juga kerusakan lingkungan dan kerugian harta benda. Hal serupa juga dijelaskan oleh Abarquez dan Mushed, (2004) Sholuf, (2007), dimana bencana disebutkan sebagai sebuah gangguan serius terhadap berfungsinya sebuah komunitas atau masyarakat yang mengakibatkan kerugian dan dampak yang meluas terhadap manusia, materi, ekonomi dan lingkungan, yang melampaui kemampuan komunitas atau masyarakat yang terkena dampak tersebut untuk mengatasinya dengan menggunakan sumber daya mereka sendiri (Isa, 2016).

Kerugian dan kerusakan yang disebabkan oleh dampak bencana mencakup lima sektor pembangunan, termasuk perumahan, infrastruktur, ekonomi produktif, sektor sosial, dan lintas sektor, dengan kerugian dan kerusakan terbesar yang terjadi di sektor perumahan (BNPB). BNPB Indonesia melaporkan bahwa total kerugian dan kerusakan yang disebabkan oleh bencana ini adalah sebesar USD 95 juta (Rp 13,82 triliun); perkiraan ini diperkirakan akan meningkat, karena rilisnya hanya termasuk data temporal (Syifa, Kadavi, \& Lee, 2019).

Selain kerugian ekonomi, bencana juga menimbulkan dampak sosial terhadap masyarakat. Dalam perspektif sosiologis, bencana seringkali dipahami berdasarkan persepsi manusia atau masyarakat, dan atas apa yang mereka rasakan terkait pengalaman emosional pada kejadiankejadian yang dapat mengancam kelangsungan hidup mereka (Pramono, 2016). Bencana telah memberikan dampak yang begitu besar baik secara fisik, psikologis maupun sosial, besarnya dampak yang ditimbulkan akibat bencana tersebut maka diperlukan pengembangan masyarakat yang memiliki kemampuan mengorganisasi, belajar dan beradaptasi dalam menghadapi bencana (Setiawan \& Pratitis, 2016).

Penelitian ini mencoba untuk melihat dampak apa saja yang di rasakan oleh para korban bencana baik dari aspek sosial maupun aspek ekonomi. Dalam penelitian ini penulis menguraikan penyebab terjadinya bencana dari segi kondisi geografis, dampak yang ditimbulkan secara langsung maupun tidak langsung serta kisah-kisah seputar bangkitnya beberapa perekonomian masyarakat.

Penelitian ini mengidentifikasi dan mendeskripsikan evaluasi dampak dan perilaku masyarakat terhadap kondisi perekonomian pasca bencana di kota Palu dan mengetahui kebijakan publik pemerintah setempat dalam menangani kasus tersebut. Penelitian ini juga mengidentifikasi dan mendeskripsikan evaluasi dampak dan perilaku masyarakat terhadap kondisi perekonomian pasca bencana di kota Palu dan mengetahui kebijakan publik pemerintah setempat dalam menangani kasus tersebut.

\section{METODE PENELITIAN}

Penelitian ini menggunakan pendekatan kualitatif dengan berbagai fenomenologi. Diskusi dalam artikel ini juga akan mencoba memaparkan tentang fenomena penjarahan pasca bencana di kota Palu. Fokus penelitian pada paper ini adalah masyarakat kota Palu yang terdampak bencana dan bagaimana kebijakan pemerintah kota dalam menyikapi kondisi perekonomian pasca 
bencana. Informan pada penelitian ini adalah masyarakat terdampak bencana. Selain itu, pengumpulan data dilakukan melalui wawancara, diskusi kelompok fokus (FGD) bersama dengan temuan ilmiah, sehingga hasil penelitian menjadi lebih akurat dan sistematis. (1) daftar wawancara, pelaksanaan wawancara dilakukan secara langsung kepada informan terpilih yang dinilai dapat memberikan jawaban-jawaban sesuai dengan data yang dibutuhkan berdasarkan permasalahan penelitian yang diajukan, (2) pedoman observasi, observasi dibutuhkan untuk melihat secara langsung seperti apa fenomena penjarahan pasca bencana di kota Palu. Data penelitian selanjutnya dianalisis berdasarkan prinsip-prinsip analisis data secara kualitatif yang dimulai dari proses pemilahan data mentah yang diperoleh dari lapangan, pengelompokan data, analisis data dan penafsiranpenafsiran data yang diperoleh.

\section{HASIL DAN PEMBAHASAN}

Berdasarkan UU Nomor 24 tahun 2007 tentang penanggulanagn bencana, bencana dikelompokkan ke dalam tiga kategori, yaitu; (1) bencana alam adalah bencana yang diakibatkan oleh peristiwa atau serangkaian peristiwa yang disebabkan oleh alam antara lain berupa gempa bumi, tsunami, gunung meletus, banjir, kekeringan, angin topan, dan tanah longsor, (2) bencana non-alam adalah bencana yang diakibatkan oleh peristiwa atau rangkaian peristiwa nonalam yang antara lain berupa gagal teknologi, gagal modernisasi, epidemi, dan wabah penyakit; dan (3) bencana sosial adalah bencana yang diakibatkan oleh peristiwa atau serangkaian peristiwa yang diakibatkan oleh manusia yang meliputi konflik sosial antarkelompok atau antar komunitas masyarakat, dan teror (Isa, 2016).
Berbagai peristiwa bencana alam yang terjadi di Indonesia dan berbagai negara lain di dunia, telah menimbulkan sebuah pengalaman tentang upaya respon dan pemulihan bencana. Upaya respon dan pemulihan bencana melibatkan hubungan antara pemerintah dan organisasi organisasi pemberi bantuan, serta masyarakat(Samad, Tawil, Kafrawi, \& Kafiah, 2018).

Gempa, Tsunami dan Likuifaksi yang melanda Kota Palu, Kabupaten Donggala dan Kabupaten Sigi pada tanggal 28 September 2018 menyisakan duka yang mendalam bagi para korban (Daswati, Samad, \& Wekke, 2019). Sumber data dari Korem 132/Tadulako Kota Palu merilis jumlah korban jiwa sebanyak 4.438 korban luka, 1.372 korban hilang/tertimbun dan 2.101 korban meninggal dunia yang tersebar di beberapa daerah yaitu Palu, Sigi, Donggala, dan Parimo. Bencana alam seperti gempa yang terjadi di Donggala,Palu dan sekitarnya bukan hanya mengakibatkan korban jiwa, tetapi juga kerusakan lingkungan dan kerugian harta benda.("Gempabumi Sulteng," n.d.).

Jumlah pengungsi di Sulawesi Tengah diperkirakan 133.631 orang tersebar di 122 titik dengan rincian 46.167 orang di Kota Palu, 41.256 orang di Kab. Sigi, 45.737 orang di Kab. Donggala dan 471 orang di Parigi Moutong. Sedangkan dampak kerusakan antara lain kerusakan pemukiman penduduk, fasilitas umum, fasilitas pemerintah, gedung milik masyarkat, fasilitas kesehatan, fasilitas perekonomian serta kerusakan infrastruktur lainnya. Total Rumah Rusak 68.451 unit, dengan rincian 65.733 unit di wilayah Palu, 897 unit di wilayah Sigi, 680 unit di wilayah Donggala dan 1.141 unit di Parigi Moutong.(Korem 132/ Tadulako). 

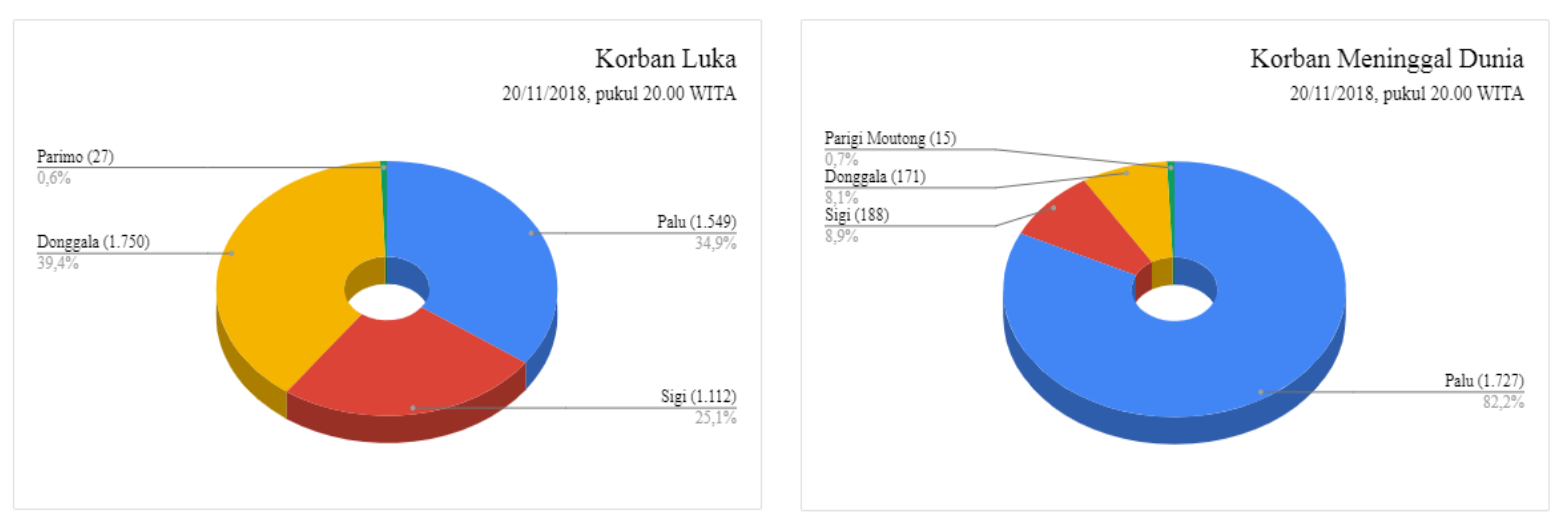

Gambar 1. Data korban bencana Kota Palu Sigi dan Donggala (Korem 132/ Tadulako)

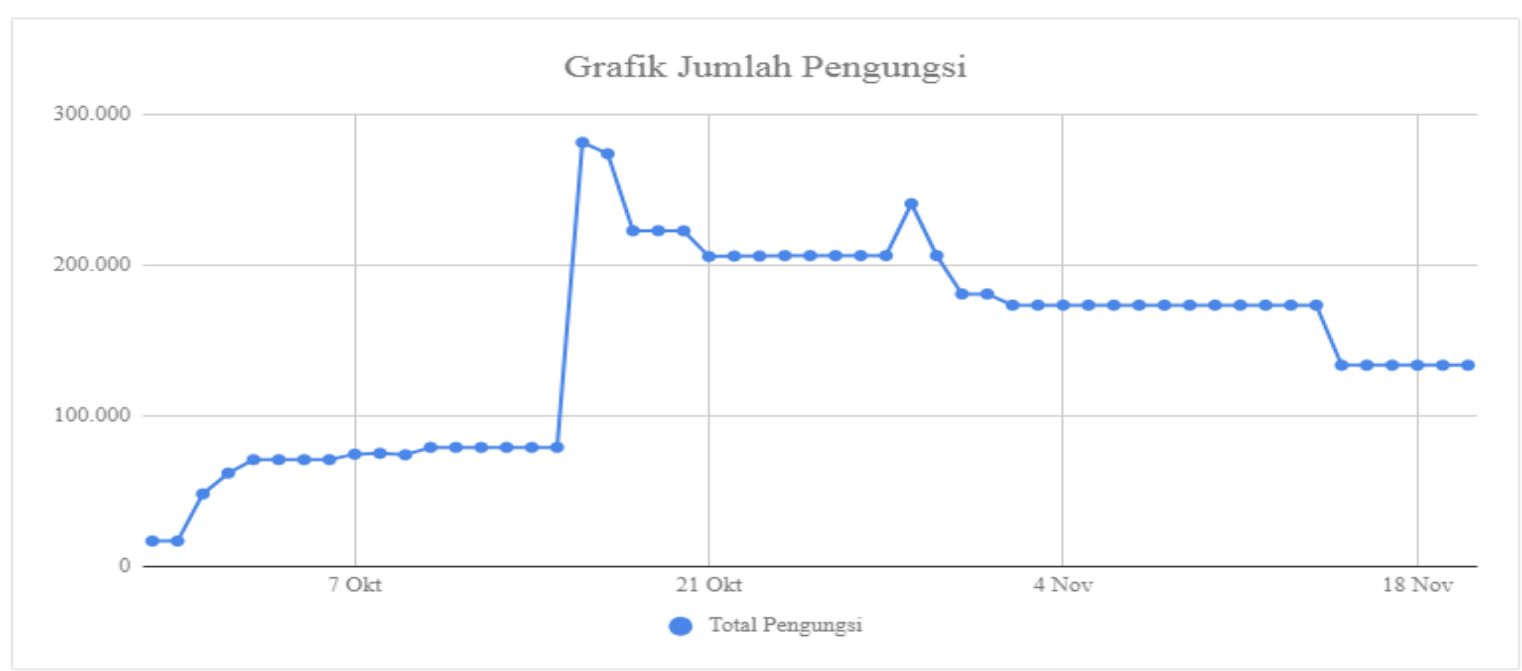

Gambar 2. Grafik jumlah pengungsi korban bencana alam kota Palu (BNPB)

Baritto (2008) berpendapat bahwa terdapat korelasi antara dampak sosial dan kerugian secara ekonomi(Modica \& Zoboli, 2016). Kondisi ekonomi penduduk adalah keadaan yang menggambarkan kehidupan manusia yang mempunyai nilai ekonomi. Kondisi ekonomi dikaji melalui tiga variabel yaitu mata pencaharian, pendapatan dan kepemilikan barang berharga(Tengah \& Selatan, 2017).

\section{Dampak Ekonomi Makro Bencana} Alam

AusAID (2005) membagi dampak ekonomi makro dari bencana alam dalam dua kelompok, yaitu dampak nyata dan dampak tidak nyata. Kedua kelompok dibawah ini akan mempengaruhi perubahan variabel-variabel ekonomi makro. 


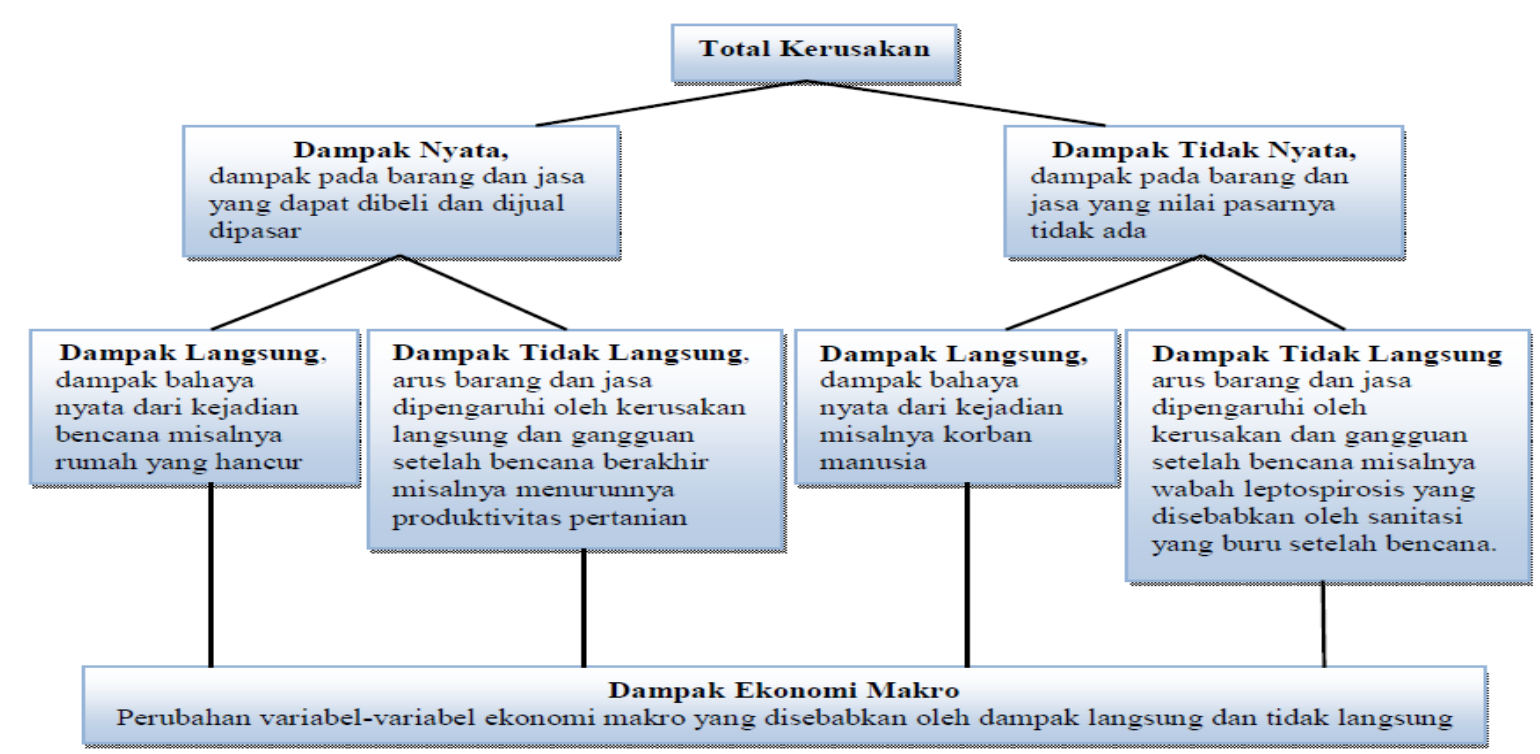

Gambar 3. Dampak Ekonomi Makro Bencana Alam

Sumber: AusAID, 2005

\section{Dampak nyata.}

Sebagian besar efek dari bencana alam adalah pada dampak langsung dan nyata, apakah itu bencana dalam skala besar ataupun menengah, hal ini harusnya menjadi perhatian dari pemerintah dalam memberikan suplai kebutuhan awal bagi para korban (Impact, Natural, On, In, \& Pacific, 2005). Karena lokasi bencana berada pada Ibukota provinsi, dimana segala pusat perekonomian berada di Kota, hal ini berimplikasi pada pasokan logistik baik itu di dalam kota atupun pasokan barang dan jasa menuju kabupaten sekitar. Rusaknya infrakstruktur pergudangan ditambah dengan adanya penjarahan yang massiv dari oknum masyarakat pada gudang-gudang suplai logistik mengakibatkan barang yang semestinya didistribusikan baik ke kota ataupun ke kabupaten akhirnya tidak dapat dilaksanakan. Disisi lain gempa bumi ini mengakibatkan pasokan listrik dan jaringan perbankan lumpuh total, sehingga masyarakat tidak mampu melakukan transaksi perbankan atau sekedar untuk menarik uang cash dari ATM. Sehingga mengakibatkan transaksi jual beli hampir vaccum dalam kurun waktu hampir sebulan setelah musibah. Pemilik toko kebutuhan harian juga hampir dipastikan menutup tokonya pasca bencana, selain karena memprioritaskan untuk menyelamatkan diri dan keluarga mereka ke lokasi pengungsian teraman mereka juga memilih untuk mengamankan harta dagangan mereka.

\section{Bencana}

kecenderungan mempengaruhi budaya, mata pencaharian, dan penalaran pada skala lokal dalam sosial ekonomi, kerugian ekonomi disebabkan oleh bencana yang secara langsung yang dapat diamati adalah kerugian rusak dan hancurnya perumahan dan sektor usaha tidak hanya berakibat pada kerugian output yang tidak bisa dihasilkan(Tengah \& Selatan, 2017). 
Tabel 1.

Penduduk Kota Palu Menurut Wilayah, dan Jenis Kelamin

\begin{tabular}{lcccr}
\hline & & \multicolumn{3}{c}{ Jenis Kelamin } \\
\cline { 3 - 5 } & Nama Kecamatan & Laki-laki & Perempuan & Laki-laki + Perempuan \\
\hline 010 & Palu Barat & 49.791 & 48.948 & 98.739 \\
020 & Palu Selatan & 61.870 & 60.882 & 122.752 \\
030 & Palu Timur & 38.526 & 37.441 & 75.967 \\
040 & Palu Utara & 19.691 & 19.383 & 39.074 \\
\hline & Kota Palu & $\mathbf{1 6 9 . 8 7 8}$ & $\mathbf{1 6 6 . 6 5 4}$ & $\mathbf{3 3 6 . 5 3 2}$
\end{tabular}

Sumber : Olahan Data Primer (2019)

Daeng Nuddin, seorang pedagang sembako memutuskan untuk tidak ikut bergabung ke lokasi pengungsian, ia dan keluarga memilih untuk tetap tinggal di rumah mereka. Tiga hari pasca bencana, mereka sama sekali tidak membuka tokonya sehingga aktifitas perekonomian tidak berjalan sama sekali. Namun demi kemanusiaan ia tetap membagikan barang makanan yang mereka miliki kepada para tetangga sesama penyintas. H. Bada, seorang pria yang berusia 70 tahun, meninggalkan Sulawesi Selatan dan hijrah ke kota Palu pada awal 1980-an dan memulai bisnis kulinernya. Pada saat bencana terjadi dia tidak meninggalkan kota Palu meskipun banyak kerabat dari Sulawesi Selatan datang ke Palu untuk menjemputnya. Dia berpegang teguh pada prinsipnya bahwa kecelakaan dan kematian yang diakibatkannya telah ditakdirkan oleh Tuhan, dan bahwa Tuhan telah menentukan apa pun yang menimpa dirinya dan keluarganya jauh sebelum dia dilahirkan ke bumi. Oleh karena itu, ia memutuskan untuk tinggal bersama keluarga besarnya (7 anak, 4 menantu, 8 2084 (Online)

cucu) dengan memasang tenda di depan tokonya dan memilih untuk tidak bergabung dengan pengungsi lain, meskipun ia, anak-anaknya dan undangundang memiliki akses ke mobil untuk mengungsi ke Sulawesi Selatan (Rajindra, Suardi, \& Sabara, 2019).

\section{Dampak tidak nyata.}

Pemberian bantuan kepada korban bencana alam menjadi perhatian khusus beberapa lembaga kemanusiaan internasional, namun terkadang terdapat kendala pada proses ini. Sebagai contoh. Negara dunia ketiga negara sering mengalami kesulitan dalam mengasimilasi bantuan yang dipasok oleh negara maju. (Alexander, Natural Disaster, Department of Geology and Geography University of Massachusetts, Amherst 2001). Selain itu evakuasi zona pemukiman bencana dapat menciptakan masalah serius, yaitu bertambahnya jumlah tunawisma. Ketiga, kemiskinan cenderung memperburuk berbagai kesulitan yang disebabkan oleh bencana alam (Disasters, n.d.). 


\section{Tabel 2}

Jumlah Korban Bencana Kota Palu

\begin{tabular}{lrrr} 
& Keterangan & $\begin{array}{c}\text { Korban meninggal } \\
\text { (jiwa) }\end{array}$ & \multicolumn{2}{c}{$\begin{array}{c}\text { Korban hilang } \\
\text { (jiwa) }\end{array}$} \\
\hline Tahap pertama & & 2.132 & 531 \\
Tahap Kedua & 476 & 39 \\
\hline Jumlah & 2.608 & 570 \\
\hline
\end{tabular}

Penduduk kota palu data sensus penduduk 2010

Sumber : Olahan Data Sekunder (2019)

Sesuai dengan data yang dirilis BNPB yaitu terdapat 2.101 korban meninggal dunia yang tersebar di beberapa daerah yaitu Palu, Sigi, Donggala, dan Parimo, begitupula dengan jumlah pengungsi korban bencana di Sulawesi Tengah diperkirakan 133.631 orang tersebar di 122 titik dengan rincian 46.167 orang di Kota Palu, 41.256 orang di Kab. Sigi, 45.737 orang di Kab. Donggala dan 471 orang di Parigi Moutong. Sedangkan dampak kerusakan antara lain kerusakan pemukiman penduduk, fasilitas umum, fasilitas pemerintah, gedung milik masyarkat, fasilitas kesehatan, fasilitas perekonomian serta kerusakan infrastruktur lainnya. Total Rumah Rusak 68.451 unit, dengan rincian 65.733 unit di wilayah Palu, 897 unit di wilayah Sigi, 680 unit di wilayah Donggala dan 1.141 unit di Parigi Moutong. Data terbaru ditemukan bahwa untuk pendataan pada tahap 1 jumlah korban jiwa sebanyak 3.679 orang, terbagi atas meninggal dunia 2.132 orang dan hilang 531 orang. Serta yang dikebumikan tidak terindentikasi 1.016 orang. Dikaebumikan di TPU Poboya dan TPU Pantoloan Boya Sedangkan untuk korban jiwa tahap 2 lanjutnya, ada ketambahan 515 orang. Yaitu meninggal dunia bertambah 476 orang, hilang bertambah 39 orang. Jadi total korban meninggal dunia dan hilang sejumlah 4.192 jiwa. Dengan melihat jumlah korban jiwa sebanyak itu jika dibandingakan dengan jumlah penduduk kota Palu pada sensus penduduk 2010 sebanyak 336532 jiwa yang mencakup mereka yang bertempat tinggal di daerah perkotaan sebanyak 310168 jiwa atau 92,17 persen dan di daerah perdesaan sebanyak 26364 jiwa atau 7,83 persen. Ini artinya, penduduk kota Palu pasca gempa diperkirakan sekitar 305.976 jiwa.

Dari data tersebut terlihat bahwa terjadi pengurangan jumlah penduduk secara signifikan pasca bencana. Hal ini mengingat bahwa pusat bencana (tsunami, gempa dan liquifasi) berada di pusat Ibukota Provinsi Sulawesi Tengah. Dimana sebahagian besar daerah padat penduduk adalah lokasi bencana, seperti perumahan nasional Balaroa dan pusat permukiman wilayah kecamatan Petobo serta pantai Talise. Pantai Talise sendiri adalah pusat lokasi kegiatan hajatan tahunan dimana pada saat gempa terjadi, adalah persiapan 
untuk kegiatan ulang tahun Provinsi Sulawesi Tengah. Sehingga masyarakat banyak berkumpul dan terkonstrasi di kegiatan tersebut

\section{Dampak Sosial Ekonomi}

Dampak yang dirasakan oleh masyarakat Kota Palu secara umum berada pada klasifikasi "berat". Kondisi sosial ekonomi masyarakat kota Palu meliputi beberapa aspek, mulai dari kondisi geografis yang berada pada zona rawan bencana, kondisi kesehatan sangat memprihatinkan pasca bencana, kondisi pemukiman warga di daerah paling parah yaitu pada Perumnas Balaroa, wilayah pemukiman Petobo serta tersebar di Kabupaten Sigi dan Donggala. Selain itu kondisi mata pencaharian warga pasca bencana cukup memprihatinkan, untuk keperluan logistik sehari-hari mereka terpaksa harus bergantung pada bantuan pemerintah, karena jaringan listrik terputus dan mengakibatkan para korban tidak mampu mengakses ATM untuk sekedar mengambil dana cash untuk membeli kebutuhan sehari-hari.

Fenomena penjarahan juga semakin massif terjadi pasca bencana. Penjarahan terjadi dimulai ketika kondisi masyarakat kekurangan logistik untuk kebutuhan makanan pokok,. Sementara bantuan dari luar kota Palu terkesan lamban, salah satu kendalanya adalah eskalasi bencana yang cukup luas, bencana terjadi di ibu kota Provinsi, serta beberapa akses jalan menuju ke lokasi pengungsian korban juga rusak akibat bencana. Selain itu, adanya informasi simpang siur dari pemerintah soal pembenaran untuk mengambil bahan makanan pada mini market berlabel tertentu, juga menjadikan masyarakat semakin terprovokasi. Kekurangan pasokan makanan, penjarahan juga terjadi pada sentra pengisian bahan bakar umum
(SPBU) di semua sudut kota. Fenomena ini terjadi karena penduduk kota Palu bukan hanya terdiri dari penduduk asli. Banyak diantara mereka adalah pendatang dari Provinsi terdekat, Sulawesi Selatan. Para warga pendatang ini memilih untuk meninggalkan kota Palu menggunakan jalur darat ke kampung halaman mereka. Sehingga untuk mendapatkan bahan bakar menuju ke kampung halaman harus berebut bersama para penduduk lainnya. Suplai terbatas dan permintaan tinggi menjadikan bahan bakar minyak pasca bencana menjadi salah satu komoditi yang menjadi sumber penjarahan masyarakat.

\section{Evaluasi Bencana Alam dan Kondisi Perekonomian Korban Bencana}

Gempa di Indonesia bisa berpotensi menyebabkan hilangnya GDP kita sampai 3\%, 30 Billion US Dollar. Kalau kita ingat Aceh waktu tsunami itu telah membuat bencana costnya adalah 4,5 billion Dollar. Yogyakarta waktu mengalami earthquake kehilangan 30\% dari GDP daerahnya("Bencana Alam dan Pengaruhnya Terhadap Perekonomian," n.d.) Semakin besar eskalasi dan jumlah korban serta infrastruktur akibat bencana, maka akan memberikan dampak ekonomi yang luas pula. Namun sekali lagi itu hanya terjadi dalam jangka pendek pasca bencana.

Para korban bencana kota Palu menjelaskan bahwa efek dari bencana alam memang memberikan kerugian yang cukup besar pada bisnis mereka, tapi itu bersifat sementara saja. Zainal, salah satu pengusaha komputer yang cukup besar di kota Palu menjelaskan, bahwa pasca bencana ia tidak serta merta meninggalkan toko yang ia tempati berjualan sekaligus tempat tinggalnya, tetapi ia tetap bertahan bersama para pengungsi lainnya di depan rumah toko mereka. Ini ia lakukan salah 
satunya adalah untuk melindungi assetnya dari para penjarah. Tiga bulan pasca bencana, Zainal kembali membuka tokonya. Dua bulan pertama sejak buka dia mengakui omzetnya menurun derastis, namun pada bulan ke lima, enam dan seterusnya, ia mengakui omzetnya sudah kembali pulih seperti sedia kala.

Disisi lain, Bahar seorang pengusaha keripik mengakui bahwa setahun setelah bencana, omset bisnisnya juga fluktuatif. Dia menjelaskan bahwa sepulang dari lokasi pengungsian bisnisnya kembali dibuka. Bulan pertama memang sangat terasa perubahan yang signifikan dari bisnisnya, namun seiring kondisi kota berangsur-angsur pulih, para warga kota juga telah kembali dari lokasi pengugsiannya. Sehingga membuat perekonomian kota Palu pelan tapi pasti juga telah kembali pulih. Mulai saat itulah bisnis dari Bahar ini kembali normal. Bahkan usaha keripik miliknya kini dipasarkan keluar kota Palu. Pasca bencana beberapa konsumen dari luar kota kemudian mencari produk unggulan dari kota ini, itulah yang diakui Bahar sebagai salah satu berkah dari kejadian yang menimpa mereka.

Begitu pula yang dirasakan oleh Indah. Wanita berusia 28 tahun yang berasal dari Madura, Jawa Tengah ini memiliki usaha yaitu warung makan dengan omset bias mencapai 1,5 juta sampai 20 juta perbulan. Saat tragedi gempa yang terjadi pada tanggal 28 September 2019, Indah beserta keluarga mengungsi di Donggala Kodi bersama rombongan warga selama satu minggu sebelum ia dan keluarganya memutuskan untuk pulang ke pulau Jawa. Selama tiga bulan Indah dan keluarganya menutup toko untuk sementara waktu dan kembali ke Palu pada bulan Januari 2019. Selama ia menutup toko, ia mengalami kerugian yang signifikan. Namun kondisi penjualannya Copyright (C) 2020, Publik (Jurnal Ilmu Administrasi), ISSN: 2301-573X (Print), ISSN: 2581-2084 (Online) sekarang sudah mulai normal kembali dan berjalan seperti biasanya.

\section{PENUTUP \\ Kesimpulan}

Dampak Sosial yang ditimbulkan dari bencana ini tergolong berat. Walaupun masyarakat kota telah familiar dengan kejadian gempa sepanjang tahun sebelumnya, namun pada bencana kali ini dirasakan dampaknya sangat besar. Hal ini dikarenakan mereka baru kali ini mengalami bencana amat dahsyat ( tiga bencana dalam waktu bersamaan) sehingga menimbulkan kepanikan luar biasa bagi warga kota.

Selain itu fenomena penjarahan pasca bencana juga menjadi ketakutan tersendiri bagi warga. Dimana mereka masih disibukkan untuk menyelamatkan anggota keluarga serta harta benda mereka akibat dari bencana, disisi lain mereka juga merasakan ancaman tindak criminal antar sesama oknum masyarakat dalam bentuk penjarahan dan pencurian.

Dari sisi ekonomi juga sangat terasa dampaknya. Sebulan pasca bencana. Kondisi ekonomi kota masih pada posisi memprihatinkan. Roda perekonomian lumpuh dan nyaris tak terlihat adanya aktifitas lain selain proses penyelamatan, recovery dan penataan fasilitas penunjang hidup utama. Namun tiga bulan pasca bencana, kondisi perekonomian masyrakat kota berangsung membaik. Pasar rakyat sudah mulai dibuka secara perlahan, dana stimulant dari pemerintah juga sudah mulai dikucurkan agar masyrakat dapat kembali menata kondisi perekonomiannya.

\section{Saran}

Bagi pemerintah kota rawan bencana, terkhusus untuk pemerintah kota Palu, kabupaten Sigi dan Kabupaten Donggala sebaiknya lebih memperhatikan pada aspek mitigasi bencana. Yaitu dengan mengeluarkan kebijakan Pendidikan 
mitigasi bencana kepada masyarakat kota. Sehingga saat bencana serupa dating kembali. Masyarakat, pemerintah dan sektor lainnya sudah melakukan langkah prepadness, agar kepanikan, chaos dan bencana social lainnya pasca bencana tidak lagi terjadi.

\section{DAFTAR PUSTAKA}

Daswati, D., Samad, M. A., \& Wekke, I. S. (2019). Collaborative Governance Dalam Pengelolaan Integrated Community Shelter Pasca Bencana Di Kota Palu Collaborative Governance in the management of Integrated Community Shelters post disaster ( ICS ) in the City of Palu.

Impact, E., Natural, O. F., On, D., In, D., \& Pacific, T. H. E. (2005). Volume 1: Research Report, 1(May).

Isa, M. (2016). Bencana Alam: Berdampak Positif Atau Negatif Terhadap Pertumbuhan Ekonomi?, 147-156.

Isa, M., Studi, P., Fakultas, M., Universitas, E., \& Surakarta, M. (2016). Bencana alam: berdampak positif atau negatif terhadap pertumbuhan ekonomi ?, 147-156.

Modica, M., \& Zoboli, R. (2016). Vulnerability, resilience, hazard, risk, damage, and loss: a socioecological framework for natural disaster analysis, 59-62. https://doi.org/10.5194/we-16-592016

Pramono, R. (2016). Perspektif Sosiologis dalam Penanggulangan Bencana. Jurnal Masyarakat \& Budaya, 18(1), 81-95.

Rajindra, R., Suardi, I., \& Sabara, Z. (2019). Diversity , Resilience , and Tragedy: Three Disasters in Palu of Indonesia, 5(2), 1592-1607.
(2017). Vulnerability zoning of earthquake disaster of Palu. International Journal of Science and Applied Science: Conference Series, 1(2),

137. https://doi.org/10.20961/ijsascs.v1i2.5 138

Samad, M. A., Tawil, Y. P., Kafrawi, M., \& Kafiah, A. Disaster Risk Management in Palu City (case study of natural disasters September 28 2018 ) (2018).

Setiawan, A., \& Pratitis, N. T. (2016). Religiusitas, Dukungan Sosial dan Resiliensi Korban Lumpur Lapindo Sidoarjo. Persona:Jurnal Psikologi Indonesia, 4(02). https://doi.org/10.30996/persona.v4i0 2.555

Syifa, M., Kadavi, P. R., \& Lee, C. W. (2019). An artificial intelligence application for post-earthquake damage mapping in Palu, central Sulawesi, Indonesia. Sensors (Switzerland), 19(3). https://doi.org/10.3390/s19030542

Tengah, S., \& Selatan, K. (2017). 1 , 1 1, $4(4), 42-52$.

Rusydi, H., Effendi, R., \& Rahmawati, R. 